\title{
An unusual failure of a laryngoscope handle
}

\author{
Steven M. Neustein, MD $\cdot$ Robert Williams, MBA
}

Received: 11 November 2008/Revised: 25 November 2008/ Accepted: 27 November 2008/Published online: 16 January 2009

(C) Canadian Anesthesiologists' Society 2009

To the Editor:

A 22-year-old male with hyperhidrosis presented for general anesthesia for a scheduled bilateral video-assisted thoracoscopy and sympathectomy. During the laryngoscopy, the handle of the Rusch (Sulzbach, Germany) laryngoscope blade separated at the weld line (a 3 Macintosh blade was used to place a double lumen endotracheal tube) (Fig. 1). As a result, the patient's trachea was intubated with a backup laryngoscope handle and 3 Macintosh blade, both of which had been previously inspected. In retrospect, the failure of the weld line could have been caused by a number of factors; such as, a hairline fracture, subtle damage if the handle was previously dropped, repeated disinfection with germicidal disposable wipes (PDI Sanicloth $^{\mathrm{TM}}$ ), or repeated cleaning with soap and water. This particular laryngoscope handle had been in service for approximately three years.

There are reports of other cases of laryngoscopy failure due to blade malfunction. In one case, the blade separated at the weld line causing the handle to impact the patient's incisors, and metal parts entered the mouth. ${ }^{1}$ In another report, blade disruption also occurred during laryngoscopy and led to separation of the attachment hinge. ${ }^{2}$ Incorrect assembly of the laryngoscope has placed the light source on the wrong side of the blade. ${ }^{3}$ In another case, the hinge pin on the handle that the blade hooks onto was reported missing, hence, the blade failed to attach properly. ${ }^{4}$ There have also been reported failures resulting in the ingestion of the blade's light bulb. ${ }^{5}$ It would not appear that a blade with a fibreoptic light source would be at risk of losing a

S. M. Neustein, MD $(\bowtie) \cdot R$. Williams, MBA Mount Sinai Medical Center, New York, USA e-mail: steve.neustein@mountsinai.org

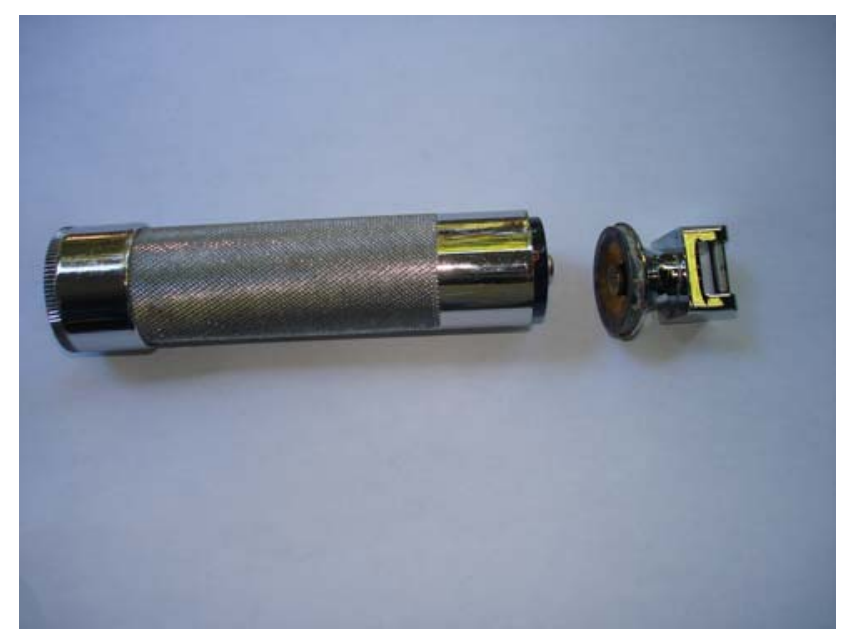

Fig. 1 The handle of the laryngoscope was fractured along the weld line

bulb, since the fibreoptic channel is imbedded in the blade. The case reported here illustrates that pressure should be applied to the blade as part of the equipment inspection, in addition to checking the blade and handle assembly for proper functioning and appropriate light intensity. Regardless of the most meticulous inspection, a second laryngoscope handle and blade should always be available as backup.

Conflicts of interest None declared.

\section{References}

1. Paterson JG. Laryngoscope breakage. Can J Anesth 2000; 47: 927.

2. Norman PH, Coveler LA, Daley MD, Dugas MJ. Failure of a laryngoscope blade. Anesth Analg 1998; 86: 448. 
3. Doddi MK, Heidemann $B H$. Unexpected failure of a laryngoscope. Anaesthesia 2004; 59: 310.

4. Jolly D, Germsheid R, Gallant B, Day G, Harrison R, Amyotte $R$. Unexpected laryngoscope failure. Can J Anesth 2002; 49: 637-8.
5. Ince Z, Tugcu D, Coban A. An unusual complication of endotracheal intubation: ingestion of a laryngoscope light bulb. Pediatr Emerg Care 1998; 14: 275-6. 